\title{
Directly Printable Frequency Signatured Chipless RFID Tag for IoT Applications
}

\author{
Hafsa ANAM ${ }^{1}$, Ayesha HABIB ${ }^{1}$, Syeda Irum JAFRI ${ }^{1}$, Yasar AMIN ${ }^{1,2}$, Hannu TENHUNEN ${ }^{2,3}$ \\ ${ }^{1}$ ACTSENA Research Group, University of Engineering and Technology, 47050- Taxila, Pakistan \\ 2 iPack VINN Excellence Center, Royal Institute of Technology, SE-16440, Stockholm, Sweden \\ ${ }^{3}$ TUCS, University of Turku, Turku-20520, Finland \\ ayesha.habib@uettaxila.edu.pk
}

Submitted November 15, 2016 / Accepted February 8, 2017

\begin{abstract}
This paper proposes a low-cost, compact, flexible passive chipless RFID tag that has been designed and analyzed. The tag is a bowtie-shaped resonator based structure with 36 slots; where each patch is loaded with 18 slots. The tag is set in a way that each slot in a patch corresponds to a metal gap in the other patch. Hence there is no mutual interference, and high data capacity of 36 bits is achieved in such compact size. Each slot corresponds to a resonance frequency in the RCS curve, and each resonance corresponds to a bit. The tag has been realized for Taconic TLX-0, PET, and Kapton ${ }^{\circledR} H N$ (DuPont ${ }^{T M}$ ) substrates with copper, aluminum, and silver nanoparticlebased ink (Cabot CCI-300) as conducting materials. The tag exhibits flexibility and well optimized while remaining in a compact size. The proposed tag yields 36 bits in a tag dimension of $24.5 \times 25.5 \mathrm{~mm}^{2}$. These 36 bits can tag $2^{36}$ number of objects/items. The ultimate high capacity, compact size, flexible passive chipless RFID tag can be arrayed in various industrial and IoT-based applications.
\end{abstract}

\section{Keywords}

Chipless, Radio Frequency Identification (RFID), Radar Cross-Section (RCS), backscattering

\section{Introduction}

Internet of things (IoT) is a combination of number of smart objects, connected via wired/wireless networks to the internet [1-5]. RFID and wireless sensor networks (WSN) are major entities of IoT system. Latest developments in RFID have enabled IoT [6]. RFID is an emerging contactless data capturing technology which is widely used for tracking purposes, theft control, health monitoring, food monitoring, luggage tracking, clothing, electronic cards and pollution control, etc., [7]. An estimated 75 billion products equipped with RFID tags will be sold yearly till the year 2019 [8]. RFID has to upswing for the latest requirement of IoT development and emergence to meet the demands of modern era [9]. Limitations of RFID technol- ogy are cost, reliability and recycling aspects [10]. The main hindrance in RF identification deployment depends on its cost per tag [11]. The emerging aspect of RFID technology and such limitations have motivated the researchers to move towards chipless tags that outperform compared to conventional chip-based tags hence tremendously reducing the cost compared to chip-based tags [10], [12]. Chipless RFID involves information coding in the form of electromagnetic signature (EMS) [13]. Chipless RFID does not need any communication protocol for identification process [13]. The most promising benefit of chipless RFID tag is that they can be printed directly on the products [8]. The reliability and versatility of chipless RFID tags can be depicted from the fact that they can replace ten trillion barcodes yearly [8].

Chipless RFID has been an interesting field for researchers because of some challenging features like enhancing the coding capacity, miniaturization, within a suitable frequency band and an enhanced read range [12]. A number of papers have appeared addressing various such aspects [12], [14-16]. One of the major aspects is to enhance data density while maintaining a suitable tag size in a reasonable frequency band [12]. Various researchers have addressed such aspect [12], [17-28]. In [29], a $3.8 \mathrm{bits} / \mathrm{cm}^{2}$ compact polarization independent, discrete slot ring resonator based chipless RFID tag has been proposed. It gives back-scattered frequency signature in a compact size with enhanced coding capacity. Another spurline resonator based chipless RFID tag in a size of $40 \times 27 \mathrm{~mm}^{2}$ yielding 8 -bit data capacity has been proposed [30]. In [27], a low-profile data encoding chipless RFID tag is designed. In this design, the data is encoded as complex natural resonances (CNRs) on the structure within an area of $24 \times 24 \mathrm{~mm}^{2}$ yielding 24-bit data. Similarly, a compact, flexible 24-bit dual polarized chipless RFID tag in a size of $20.6 \times 19.9 \mathrm{~mm}^{2}$ is designed [7]. It discusses flexibility in very compact size.

In this paper, a novel 36-bit chipless RFID tag is presented. The novelty of the tag relies on its flexibility, compact size and high data capacity of 36 bits, which has not been done so far in such a compact size. Also, the tag is 


\begin{tabular}{|c|c|c|c|c|c|}
\hline Parameters & Tag-1 & Tag-2 & Tag-3 & Tag-4 & Tag-5 \\
\hline Substrate & Taconic TLX-0 & PET & PET & Kapton ${ }^{\circledR}$ HN & Kapton ${ }^{\circledR}$ HN \\
\hline Permittivity & 2.45 & 2.9 & 2.9 & 3.5 & 3.5 \\
\hline Radiator & Copper & Aluminum & Silver nano ink & Aluminum & Silver nano ink \\
\hline Thickness [mm] & 0.035 & 0.007 & 0.015 & 0.007 & 0.015 \\
\hline Trans. bits & 36 & 36 & 36 & 36 & 36 \\
\hline No. of tagged objects & $68,719,476,736$ & $68,719,476,736$ & $68,719,476,736$ & $68,719,476,736$ & $68,719,476,736$ \\
\hline Freq. band [GHz] & $5-15.5$ & $5.3-18.2$ & $4-18.2$ & $5-17$ & $4-17$ \\
\hline Size $\left[\mathrm{mm}^{2}\right]$ & $27 \times 26$ & $24.5 \times 25.5$ & $24.5 \times 25.5$ & $24.5 \times 25.5$ & $24.5 \times 25.5$ \\
\hline Flexibility & $\mathrm{x}$ & $\checkmark$ & $\checkmark$ & $\checkmark$ & $\checkmark$ \\
\hline
\end{tabular}

Tab. 1. Characteristic comparison table.

equipped with flexibility which is the recent requirement of RFID industry applications especially green electronics. PET and Kapton ${ }^{\circledR} \mathrm{HN}$ are considered in the tag as flexible substrates, whereas, silver nanoparticle-based ink is used for cheap printability of the design. The conductivity of nanoparticle-based ink is $9 \times 10^{6} \mathrm{~S} / \mathrm{m}$.

The tag is a resonator based structure that is excited by a linear polarized incident plane wave in a tag dimension of $24.5 \times 25.5 \mathrm{~mm}^{2}$. Firstly, copper is used as a radiator for the Taconic TLX-0 substrate to achieve desired RCS response. Then, aluminum and silver nanoparticlebased ink are deployed as a radiator for PET and Kapton ${ }^{\circledR} \mathrm{HN}$ substrates to achieve printability along with flexibility in a reduced tag design. The entire tag yields a data capacity of 36-bit, hence $2^{36}$ number of objects can be tagged. The frequency ranges for Taconic TLX-0 along with copper as the radiator is $5-15.5 \mathrm{GHz}$, for PET along with aluminum is $5.3-18.2 \mathrm{GHz}$ and $4-18.2 \mathrm{GHz}$ with silver nanoparticle-based ink. The frequency range for Kapton ${ }^{\circledR} \mathrm{HN}$ along with aluminum as the radiator is 5-17 GHz and 4-17 GHz for silver nanoparticle-based ink as a radiator.

\section{Theory and Fundamental Principle}

RFID involves electromagnetic waves to identify a tagged object [13] remotely. The tag is a resonator structure, where each slot corresponds to one dip and each dip corresponds to one bit. Hence 36 slots yield 36 bits data density. 36-bit tag is designed using CST STUDIO SUITE $^{\circledR}$. The tag is excited by using linearly incident plane wave. The E-field plane wave equation is given as

$$
\mathbf{E}(x, y, z, t)=E_{0} \exp [\mathrm{j}(w t-k z)] \hat{\mathbf{x}}+E_{0} \exp \left[\mathrm{j}\left(w t-k z+\frac{\pi}{2}\right)\right] \hat{\mathbf{y}}
$$

where $\mathbf{E}$ is an electric field, $w$ is the angular frequency, $t$ is time, $k$ is wave vector, $(x, y, z)$ is the position vector.

Chipless RFID tags are classified as retransmission based tags and backscattering based tags [31]. The main working principle of chipless RFID tags is backscattering. Identification is based on unique frequency signature generation in a desired frequency range that is measured as radar cross-section (RCS) of the tag [12], [32]. The radar cross-section (RCS) versus frequency shows the electromagnetic behavior of tags. The RCS is analyzed at far-field distance given by Fraunhoffer distance formula

$$
R=\frac{2 D^{2}}{\lambda}
$$

where $D$ is the radiator's largest dimension and $\lambda$ is the wavelength of radio wave [33].

To measure RCS response of chipless RFID tag, we need two antennas: one for transmitting and the other for receiving. Reader antenna sends an electromagnetic wave (EW) also known as 'interrogator signal' towards the tag [34]. The tag then encodes the data information in that signal and sends the 'backscattered signal' containing encoded information towards the reader [35]. The back-
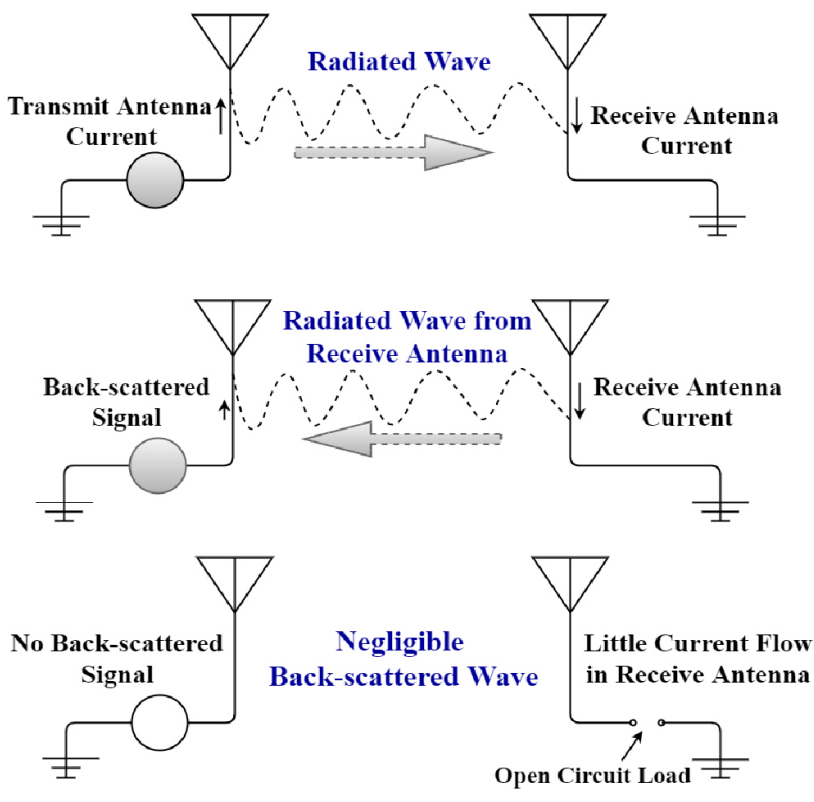

Fig. 1. Simplified physics of backscattering phenomena. 


\begin{tabular}{|c|c|c|c|c|c|c|c|c|c|c|c|}
\hline \multirow{2}{*}{\multicolumn{2}{|c|}{$\begin{array}{l}\text { Parameters } \\
\text { Substrate }\end{array}$}} & \multicolumn{2}{|c|}{ Tag-1 } & \multicolumn{2}{|c|}{ Tag-2 } & \multicolumn{2}{|c|}{ Tag-3 } & \multicolumn{2}{|c|}{ Tag-4 } & \multirow{2}{*}{\multicolumn{2}{|c|}{$\begin{array}{c}\text { Tag-5 } \\
\text { Kapton }{ }^{\otimes} \mathrm{HN}\end{array}$}} \\
\hline & & \multicolumn{2}{|c|}{ Taconic TLX-0 } & \multicolumn{2}{|c|}{ PET } & \multicolumn{2}{|c|}{ PET } & \multicolumn{2}{|c|}{ Kapton ${ }^{\otimes} \mathrm{HN}$} & & \\
\hline \multicolumn{2}{|c|}{ Radiator } & \multirow{2}{*}{\multicolumn{2}{|c|}{$\begin{array}{c}\text { Copper } \\
{[\mathrm{mm}]}\end{array}$}} & \multirow{2}{*}{\multicolumn{2}{|c|}{$\underset{[\mathrm{mm}]}{\text { Aluminum }}$}} & \multirow{2}{*}{\multicolumn{2}{|c|}{$\begin{array}{l}\begin{array}{c}\text { Silver nano- } \\
\text { particle-based ink } \\
{[\mathrm{mm}]}\end{array} \\
\end{array}$}} & \multirow{2}{*}{\multicolumn{2}{|c|}{$\underset{[\mathrm{mm}]}{\text { Aluminum }}$}} & \multirow{2}{*}{\multicolumn{2}{|c|}{$\begin{array}{c}\text { Silver nano- } \\
\text { particle-based ink } \\
{[\mathrm{mm}]}\end{array}$}} \\
\hline $\begin{array}{c}\text { Slot } \\
\text { width }\end{array}$ & $\begin{array}{l}\text { Metal } \\
\text { width }\end{array}$ & & & & & & & & & & \\
\hline$S 1$ & $M 1$ & 0.3 & 0.2 & 0.4 & 0.5 & 0.5 & 0.4 & 0.6 & 0.3 & 0.6 & 0.3 \\
\hline$S 2$ & $M 2$ & 0.3 & 0.2 & 0.2 & 0.2 & 0.2 & 0.2 & 0.2 & 0.2 & 0.2 & 0.2 \\
\hline$S 3$ & $M 3$ & 0.3 & 0.2 & 0.2 & 0.2 & 0.2 & 0.2 & 0.2 & 0.2 & 0.2 & 0.2 \\
\hline$S 4-S 32$ & $M 4-M 32$ & 0.3 & 0.2 & 0.3 & 0.2 & 0.3 & 0.2 & 0.3 & 0.2 & 0.3 & 0.2 \\
\hline$S 33$ & M33 & 0.3 & 0.3 & 0.3 & 0.6 & 0.3 & 0.6 & 0.3 & 0.6 & 0.3 & 0.6 \\
\hline$S 34$ & M34 & 0.3 & 0.3 & 0.3 & 0.5 & 0.3 & 0.5 & 0.3 & 0.5 & 0.3 & 0.5 \\
\hline S35 & M35 & 0.6 & 1 & 0.6 & 0.7 & 0.6 & 0.7 & 0.6 & 0.7 & 0.6 & 0.7 \\
\hline$S 36$ & M36 & 0.4 & 0.9 & 0.4 & 0.7 & 0.4 & 0.7 & 0.4 & 0.7 & 0.4 & 0.7 \\
\hline
\end{tabular}

Tab. 2. Proposed tags dimensions.

scattered signal contains unique frequency signature for identification. So, there is no need for any integrated circuit to encode the data. Figure 1 shows the backscattering phenomenon.

The power received from a transmitting antenna by a receiving antenna is given by Friis transmission equation [36]

$$
\frac{P_{\mathrm{RX}}}{P_{\mathrm{TX}}}=\left(\frac{\lambda}{4 \pi r}\right)^{2} G_{\mathrm{TX}} G_{\mathrm{RX}}
$$

where $r$ is the distance between transmitter and receiver, $G_{\mathrm{TX}}$ and $G_{\mathrm{RX}}$ are the gain of the transmitter and receiver, $P_{\mathrm{TX}}$ is power transmitted and $P_{\mathrm{RX}}$ is power received.

All the tagged items/objects should lie in the read range/working space of system for proper RFID operation [37]. The maximum theoretical read range of chipless RFID system can be calculated from (4) [23], [38]

$$
R^{\max }=\sqrt[4]{P_{\mathrm{TX}} G_{\mathrm{TX}} G_{\mathrm{RX}} \frac{\lambda^{2}}{(4 \pi)^{3} P_{\mathrm{RX}}} \sigma_{\min }}
$$

where $P_{\mathrm{TX}}$ is transmitting power, $G_{\mathrm{TX}}$ is transmitting antenna gain, $G_{\mathrm{RX}}$ is receiving antenna gain, $\lambda$ is the wavelength, $P_{\mathrm{RX}}$ is the sensitivity of the receiver and $\sigma_{\min }$ is the most minimum RCS level possible to be detected by the reader.

\section{Proposed Tag Design}

The proposed tag is loaded with 36 slots, each of varying length in a tag dimension of $24.5 \times 25.5 \mathrm{~mm}^{2}$. Each slot is numbered according to its length. Each slot of different length corresponds to a dip that resonates at a particular frequency. So there are 36 dips corresponding to 36 bits yielding $2^{36}$ number of possible tag ID combinations. The tag is designed in a way that each slot in upper patch corresponds to metal in the lower patch and vice versa. Therefore, the slots are at alternate positions with metal gaps for adjacent patches. Hence, each slot will be of different length, resonating at a different frequency. Ultimately, there will be no mutual coupling and high dense data in a compact size is achieved while fully utilizing the frequency band. The proposed tag design is shown in Fig. 2.

There are five tags that have been designed using Taconic TLX-0, PET, and Kapton ${ }^{\circledR} \mathrm{HN}$ substrates along with copper, aluminum and silver nanoparticle-based ink as radiators. We can analyze that along with changing substrate and radiator; there is variation in tag electrical properties. The tag has been designed and optimized for different substrates, so there is a slight variation in dimensions while optimizing the tag for flexible substrates. The detailed characteristic comparison of all the tags is shown in Tab. 1. It can be observed from Tab. 1 that the tag has been initially designed for the Taconic TLX- 0 substrate. Then the tag has further been optimized for PET substrate to achieve flexibility. To meet the modern application requirements there is a trade-off between the bandwidth and

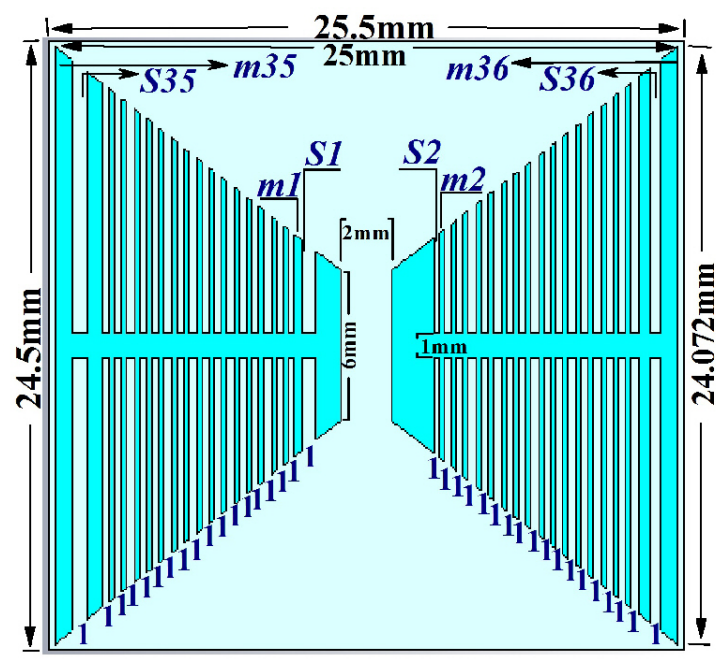

Fig. 2. The layout of designed tag. 
tag size/flexibility. Moreover, for efficient band utilization while using flexible substrate, the tag design is optimized for Kapton ${ }^{\mathbb{B}} \mathrm{HN}$.

\section{Results and Discussion}

The proposed tag design encodes 36 bits data. The tag has been designed for different substrates of varying electrical properties using different conducting materials. The detailed analysis of tag dimensions for all the designed tags is shown in Tab. 2.

\subsection{Taconic TLX-0 Substrate}

The tag designed using Taconic TLX-0 substrate and copper radiator is referred as 'Tag-1'. The RCS vs. frequency response for Tag-1 is shown in Fig. 3. The electrical permittivity of Taconic TLX-0 is 2.45 , deployed using copper as a radiator with a thickness of $0.035 \mathrm{~mm}$. 36-bit tag response has been analyzed in the frequency range between $5 \mathrm{GHz}$ and $15.5 \mathrm{GHz}$.

\subsection{PET Substrate}

Tags referred as 'Tag-2,' and 'Tag-3' are designed using PET substrate along with aluminum and silver nanoparticle-based ink as conducting materials, respectively. The electrical permittivity of PET is 2.9. The tag designed using PET as substrate and aluminum as radiator is referred as 'Tag-2'. The RCS vs. frequency response for Tag-2 is shown in Fig. 4. Aluminum used as radiator has thickness of $0.007 \mathrm{~mm}$. The tag yields 36 bits in the frequency range of 5.3-18.2 GHz.

The tag represented as 'Tag-3' is designed using PET substrate along with silver nanoparticle-based ink as conducting material. The RCS response for Tag-3 is shown in Fig. 5. The thickness of the silver nanoparticle-based ink is $0.015 \mathrm{~mm}$. The RCS curve for Tag-3 lies in the frequency range of 4-18.2 GHz.

\subsection{Kapton ${ }^{\circledR}$ HN Substrate}

The tags referred as 'Tag-4,' and 'Tag-5' are designed on Kapton ${ }^{\circledR} \mathrm{HN}$ substrate using aluminum and silver nanoparticle-based ink as radiators.

The electrical permittivity of Kapton ${ }^{\circledR} \mathrm{HN}$ is 3.5 . Kapton ${ }^{\circledR} \mathrm{HN}$ is deployed for its easy availability and lowcost along with flexibility. By changing the radiator, there is variation in resonances of the tag. 'Tag-4' has been designed using aluminum radiator on Kapton ${ }^{\circledR} \mathrm{HN}$ substrate. The RCS vs. frequency response for Tag-4 is shown in Fig. 6. Aluminum in Tag-4 has thickness of $0.007 \mathrm{~mm}$ and yields 36-bit data in the frequency range between $5 \mathrm{GHz}$ and $17 \mathrm{GHz}$.

The tag designed using silver nano ink radiator on Kapton ${ }^{\circledR} \mathrm{HN}$ substrate is referred as 'Tag-5'. The RCS response for Tag-5 along with fabricated design is shown in Fig. 7.

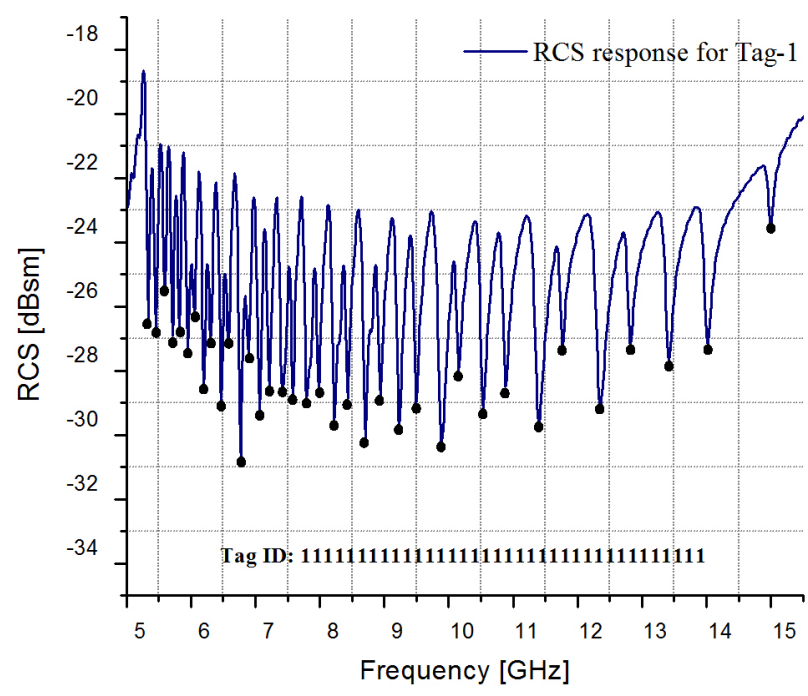

Fig. 3. RCS response for Tag-1.

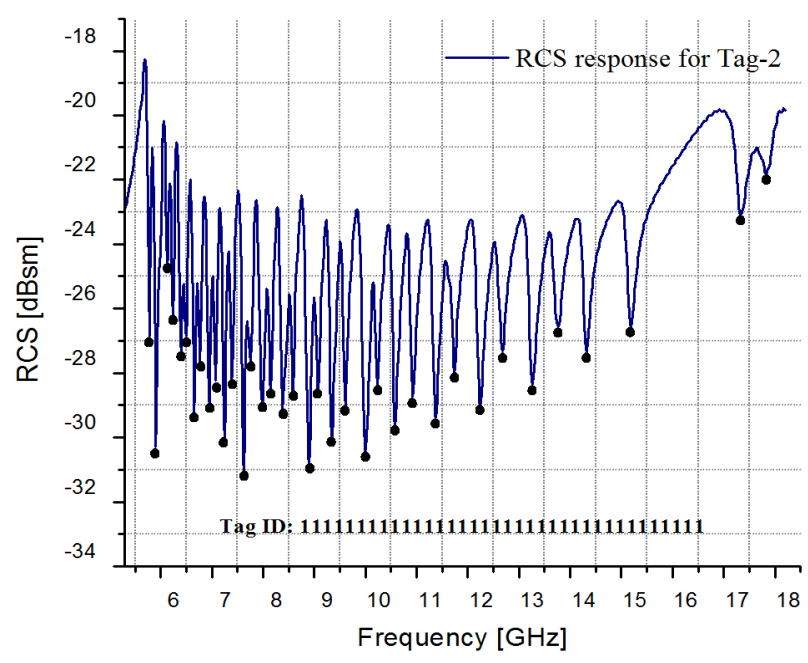

Fig. 4. RCS response for Tag-2.

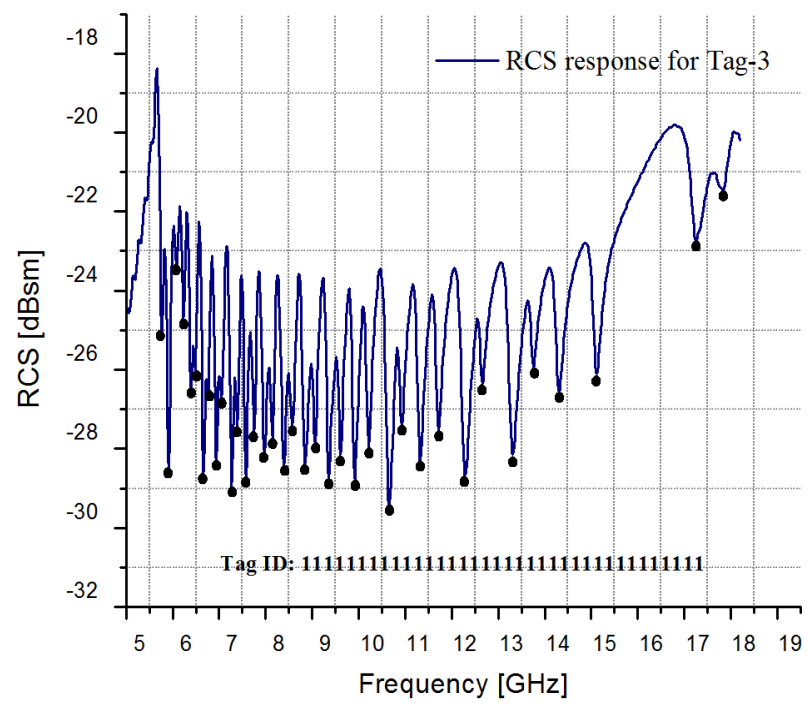

Fig. 5. RCS response for Tag-3. 


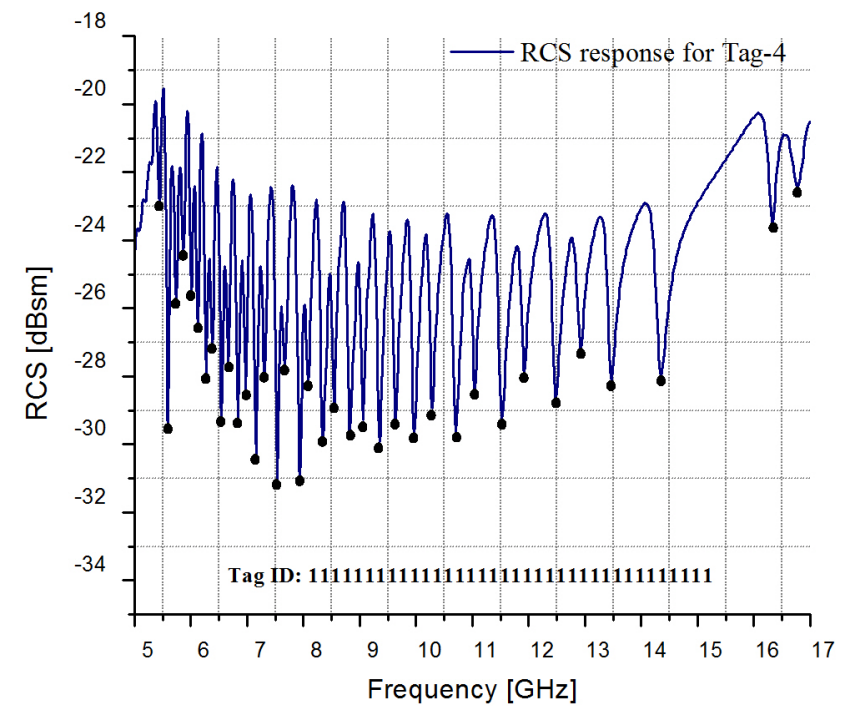

Fig. 6. RCS response for Tag-4.

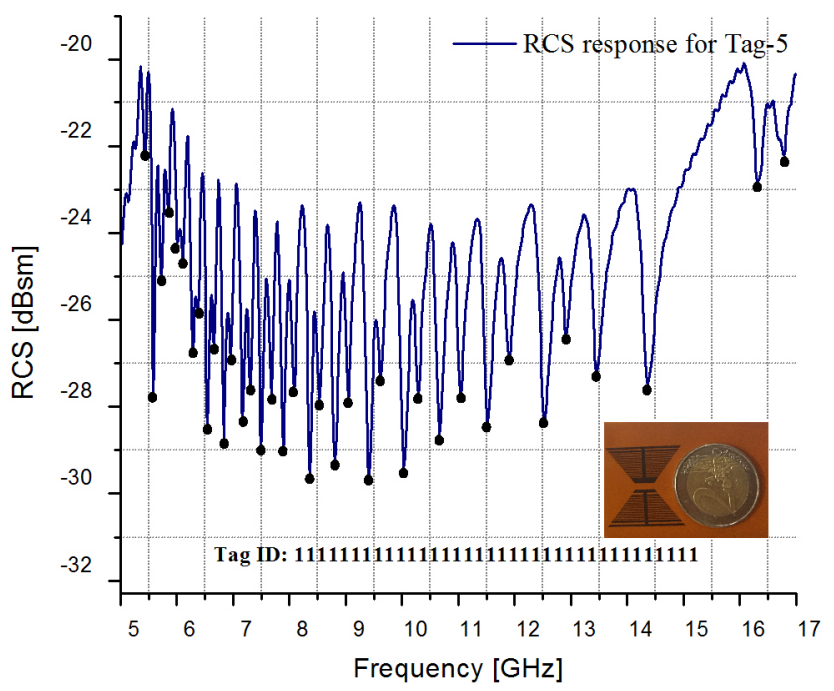

Fig. 7. RCS response for Tag-5.

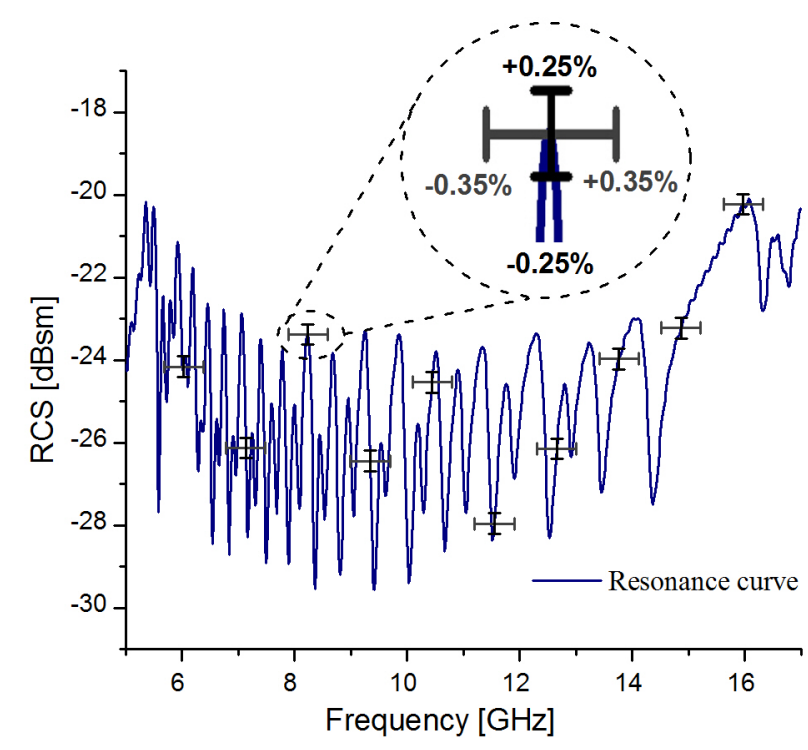

Fig. 8. Reliability curve of Tag.
The tag RCS response for 36 bits using silver nano ink radiator of $0.015 \mathrm{~mm}$ thickness lies in the frequency range of $4-17 \mathrm{GHz}$. We analyze that by the change of conducting material, there is variation in resonances of the tags.

To analyze the reliability parameters, five prototypes of each substrate are manufactured and tested. The corresponding reliable performance is shown in Fig. 8. It has been observed that the tag shows $0.25 \%$ tolerance in RCS values and exhibits $0.35 \%$ tolerance in the frequency band of interest.

By changing the substrate, there is variation in electrical properties which consequently results in frequency shift in RCS curve. With decreasing permittivity, there is a right shift in resonances which can be analyzed from ' $L S B$ ' (Least significant bit) of comparison graph shown in Fig. 9. A comparative analysis of previous research works and the proposed research work is shown below in Tab. 3 .

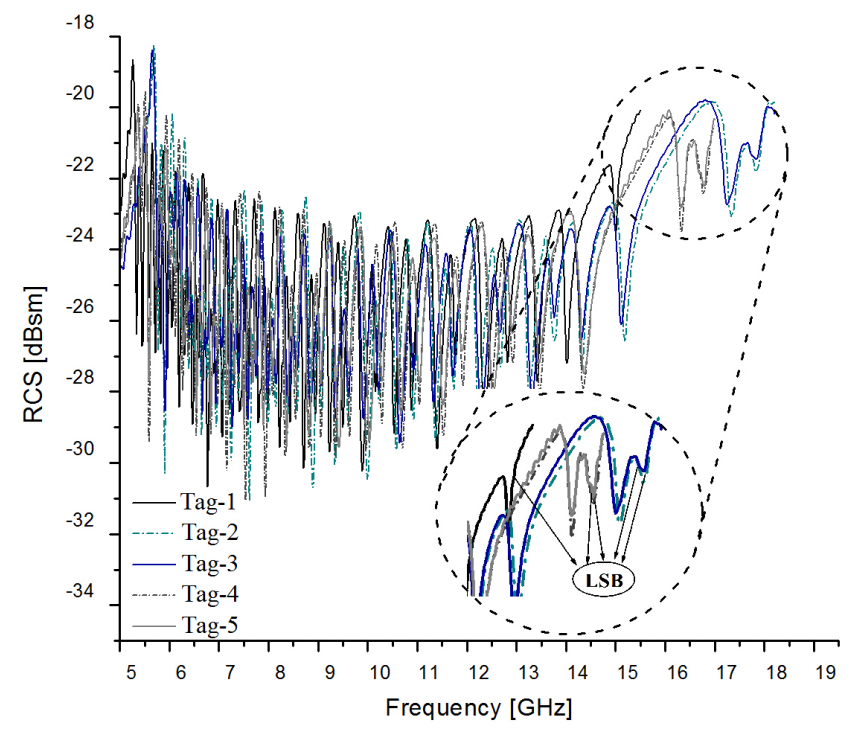

Fig. 9. Comparison graph of all presented tags.

\begin{tabular}{|c|c|c|c|}
\hline Parameters & $\begin{array}{c}\text { Paper 1 } \\
{[36]}\end{array}$ & $\begin{array}{c}\text { Paper 2 } \\
\text { [7] }\end{array}$ & $\begin{array}{c}\text { Proposed } \\
\text { paper }\end{array}$ \\
\hline Trans. Bits & 12 & 24 & 36 \\
\hline $\begin{array}{c}\text { No. of } \\
\text { tagged items }\end{array}$ & 4096 & 16777216 & $68,719,476,736$ \\
\hline Size [mm²] & $35 \times 33$ & $20.6 \times 19.9$ & $24.5 \times 25.5$ \\
\hline Flexibility & $\mathrm{x}$ & $\checkmark$ & $\checkmark$ \\
\hline
\end{tabular}

Tab. 3. Comparison table.

To analyze different coded combinations, various tag ID's have been generated, simulated and tested. A comparative analysis of presented full tag with two different tag ID's along with their prototypes is shown in Fig. 10. Tag-A corresponds to all 1's with a tag ID 


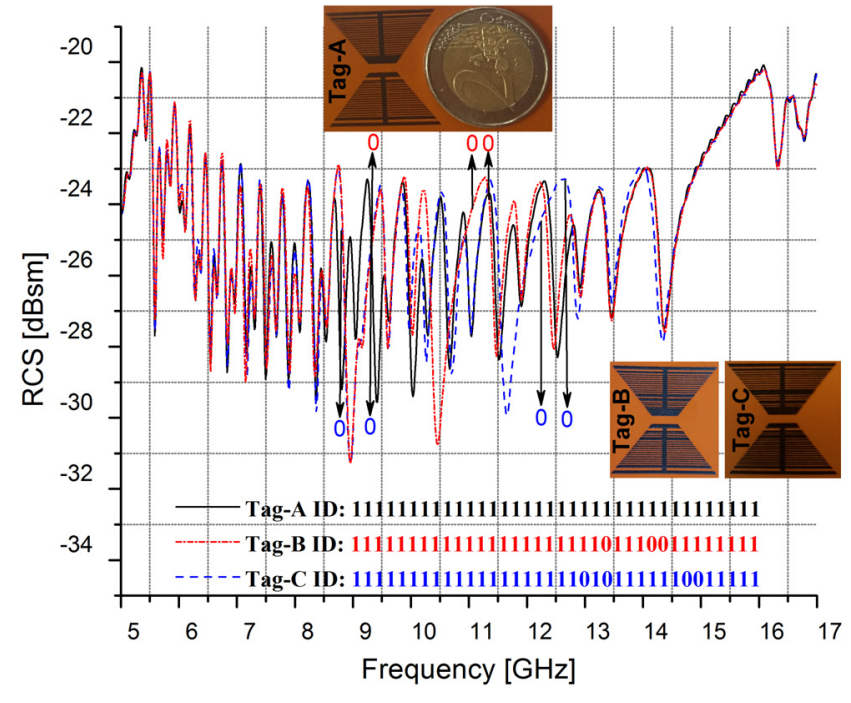

Fig. 10. Comparison of different ID combinations.

111111111111111111111111111111111111. For Tag-B, $S 9, S 10$ and $S 14$ slots are shorted leading towards a coded combination of ID having ' 0 ' bits: 111111111111111111111101110011111111. Again, another data word having ' 0 ' bits representing tag ID: 111111111111111111110101111110011111 is presented as Tag-C by shorting $S 6, S 7, S 14$, and $S 16$. It has been analyzed that the occurrence of 0-bit has a slight effect on the amplitude and resonance frequency of neighboring peaks.

\section{Measured Results}

After testing, the results are measured and analyzed. The measured and computed results are shown in Fig. 11. RCS evaluation for each bit at a particular resonance can be calculated theoretically by using (5) [39]

$$
f=\frac{c}{2 L} \sqrt{\frac{2}{\varepsilon_{\mathrm{r}}+1}}
$$

where $\varepsilon_{\mathrm{r}}$ is the relative permittivity of substrate, $L$ is the slot length and $c$ is the speed of light.

The experimental setup of chipless RFID for RCS evaluation includes two horn antennas; one transmitting and the other receiving as shown in Fig. 12. The tag deployed on the item is set at a far-field distance from the antennas. The transmitting antenna bombards an interrogator signal on the tag and receiver antenna then reads its response for identification using Vector Network Analyzer (VNA) R\&S ${ }^{\circledR} Z V L 13$. The tag is printed using a table-top printer available from Dimatix “DMP2800” inkjet printer.

\section{Conclusion}

The research has proposed a novel, 36-bit passive chipless RFID resonator based tag. The tag has been designed, printed and tested. The tag consists of slots of dif-

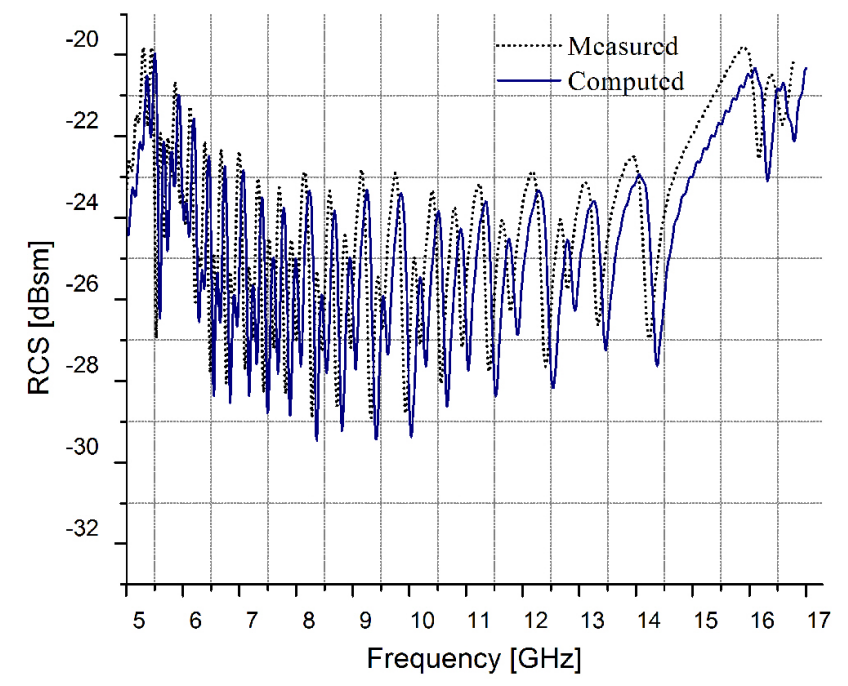

Fig. 11. Measured and computed RCS response.

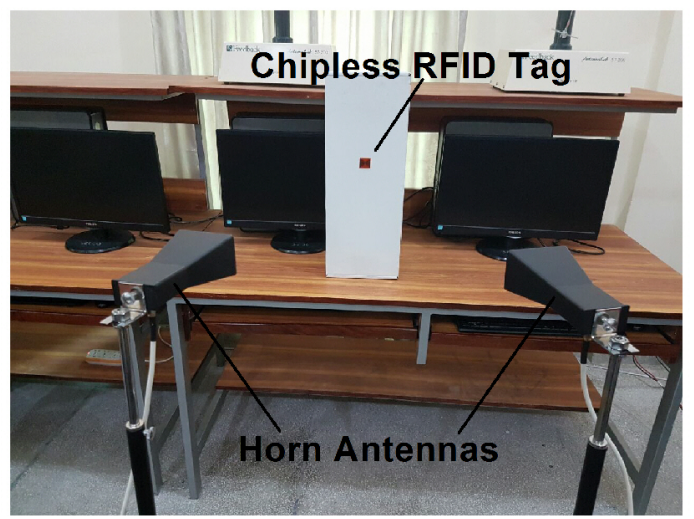

Fig. 12. Experimental set-up.

ferent widths and lengths etched on the radiating patch. The proposed tag is of $24.5 \times 25.5 \mathrm{~mm}^{2}$ dimensions, designed on Taconic TLX-0, PET, and Kapton ${ }^{\circledR} \mathrm{HN}$ substrates with copper, aluminum, and silver nanoparticlebased ink as radiators. The novelty of the tag relies on its compact size, high-density data and flexibility; deployed all together for green electronics, economic, environmentfriendly and IoT-based applications.

\section{Acknowledgments}

This work was financially supported by Vinnova (The Swedish Governmental Agency for Innovation Systems) and University of Engineering and Technology Taxila, Pakistan through the Vinn Excellence Centers program and ACTSENA research group funding, respectively.

\section{References}

[1] KHAN, U. H., ASLAM, B., AZAM, M. A., et al. Compact RFID enabled moisture sensor. Radioengineering, Sept. 2016, vol. 25, no. 3, p. 449-456. DOI: 10.13164/re.2016.0449 
[2] GUBBI, J., BUYYA, R., MARUSIC, S., et al. Internet of Things (IoT): A vision, architectural elements, and future directions. Future Generation Computer Systems, 2013, vol. 29, no. 7, p. 1645-1660. DOI: 10.1016/j.future.2013.01.010

[3] WANT, R., SCHILIT, B. N., JENSON, S. Enabling the internet of things. Computer, 2015, vol. 48, no. 1, p. 28-35. DOI: 10.1109/MC.2015.12

[4] TRUONG, H. L., DUSTDAR, S. Principles for engineering IoT cloud systems. IEEE Cloud Computing, 2015, vol. 2, no. 2, p. 68 to 76 . DOI: $10.1109 / \mathrm{MCC} .2015 .23$

[5] KHAN, M. S., ISLAM, M. S., DENG, H. Design of a reconfigurable RFID sensing tag as a generic sensing platform towards the future internet of things. IEEE Internet of Things Journal, 2014, vol. 1, no. 4, p. 300-310. DOI: 10.1109/JIOT.2014.2329189

[6] FUQAHA, A. A., GUIZANI, M., MOHAMMADI, M., et al. Internet of Things: A survey on enabling technologies, protocols, and applications. IEEE Communications Surveys \& Tutorials, 2015, vol. 17, no. 4, p. 2347-2376. DOI: 10.1109/COMST.2015.2444095

[7] JAVED, N., HABIB, A., AMIN, Y., et al. Directly printable moisture sensor tag for intelligent packaging. IEEE Sensors Journal, 2016, vol. 16, no. 16, p. 6147-6148. DOI: 10.1109/JSEN.2016.2582847

[8] IDTechEx, Printed and Chipless RFID Forecasts, Technologies \& Players 2009-2019. [Online] Available at: www.IdtechEx.com

[9] RAZZAQUE, M. A., JEVRIC, M. M., PALADE, A. Middleware for Internet of Things: A survey. IEEE Internet of Things Journal, 2016, vol. 3, no. 1, p. 70-95. DOI: 10.1109/JIOT.2015.2498900

[10] RODRIGUES, R. A. A., GURJAO, E. C., de ASSIS, F. M. Radar cross-section and electric field analysis of backscattering elements of chipless RFID tag. In IEEE RFID Technology and Applications Conference (RFID-TA). Tampere (Finland), 2014, p. 103-108. DOI: 10.1109/RFID-TA.2014.6934209

[11] KARMAKAR, N. C. Tag, You're it radar cross section of chipless RFID tags. IEEE Microwave Magazine, 2016, vol. 17, no. 7, p. 64 to 74 . DOI: $10.1109 /$ MMM.2016.2549160

[12] KHAN, M. M., TAHIR, F. A., CHEEMA, H. M. High capacity polarization sensitive chipless RFID tag. In IEEE International Symposium on Antennas and Propagation \& USNC/URSI National Radio Science Meeting. Vancouver (Canada), 2015, p. 1770-1771. DOI: 10.1109/APS.2015.7305274

[13] VENA, A., PERRET, E., TEDJINI, S. High-capacity chipless RFID tag insensitive to the polarization. IEEE Transactions on Antennas and Propagation, 2012, vol. 60, no. 10, p. 4509-4515. DOI: 10.1109/TAP.2012.2207347

[14] SHAO, B., AMIN, Y., CHEN, Q., et al. Directly printed packaging-paper-based chipless RFID tag with coplanar LC resonator. IEEE Antennas and Wireless Propagation Letters, Feb. 2013, vol. 12, p. 325-328. DOI: 10.1109/LAWP.2013.2247556

[15] VENA, A., PERRET, E., TEDJINI, S. Design of compact and auto-compensated single-layer chipless RFID tag. IEEE Transactions on Microwave Theory and Techniques, 2012, vol. 60, no. 9, p. 2913-2924. DOI: 10.1109/TMTT.2012.2203927

[16] AMIN, Y., CHEN, Q., ZHENG, L. R., et al. Development and analysis of flexible UHF RFID antennas for 'green' electronics. Progress In Electromagnetics Research, 2012, vol. 130, p. 1-15. DOI: 10.2528 /PIER12060609

[17] FENG, Y., XIE, L., CHEN, Q., et al. Low-cost printed chipless RFID humidity sensor tag for intelligent packaging. IEEE Sensors Journal, June 2015, vol. 15, no. 6, p. 3201-3208. DOI: 10.1109/JSEN.2014.2385154
[18] BHUIYAN, M. S., AZAD, A., KARMAKAR, N. Dual-band modified complementary split ring resonator (MCSRR) based multi-resonator circuit for chipless RFID tag. In 2013 IEEE Eighth International Conference on Intelligent Sensors, Sensor Networks and Information Processing. Melbourne (VIC), 2013, p. 277-281. DOI: 10.1109/ISSNIP.2013.6529802

[19] AMIN, E. M., BHUIYAN, M. S., KARMAKAR, N. C., et al. Development of a low cost printable chipless RFID humidity sensor. IEEE Sensors Journal, 2014, vol. 14, no. 1, p. 140-149. DOI: 10.1109/JSEN.2013.2278560

[20] VENA, A., PERRET, E., TEDJINI, S., et al. Design of chipless RFID tags printed on paper by flexography. IEEE Transactions on Antennas and Propagation, 2013, vol. 61, no. 12, p. 5868-5877. DOI: 10.1109/TAP.2013.2281742

[21] AMIN, E. M., KARMAKAR, N., PRERADOVIC, S. Towards an intelligent EM barcode. In 7 th International Conference on Electrical and Computer Engineering (ICECE). Dhaka (Bangladesh), 2012, p. 826-829. DOI: 10.1109/ICECE.2012.6471678

[22] MARTINEZ-IRANZO, U., MORADI, B., GARCIA-GARCIA, J. Open ring resonator structure for compact chipless RFID tags. In IEEE MTT-S International Microwave Symposium. Phoenix (AZ, USA), 2015, p. 1-3. DOI: 10.1109/MWSYM.2015.7166790

[23] PRERADOVIC, S., KARMAKAR, N. Design of fully printable planar chipless RFID transponder with 35-bit data capacity. In The European Microwave Conference EuMC. Rome (Italy), 2009, p. 013-016. ISBN: 978-1-4244-4748-0

[24] ISLAM, M. A., KARMAKAR, N. C. Real-world implementation challenges of a novel dual-polarized compact printable chipless RFID tag. IEEE Transactions on Microwave Theory and Techniques, 2015, vol. 63, no. 12, p. 4581-4591. DOI: 10.1109/TMTT.2015.2495285

[25] HERROJO, C., NAQUI, J., PAREDES, F., et al. Spectral signature barcodes implemented by multi-state multi-resonator circuits for chipless RFID tags. In IEEE MTT-S International Microwave Symposium (IMS). San Francisco (CA, USA), 2016, p. 1-4. DOI: 10.1109/MWSYM.2016.7539981

[26] HARAZ, O. M., ASHRAF, M., ALSHEBILI, S., et al. Design of UWB chipless RFID tags using 8-bit open circuit stub resonators. In 17th International Symposium on Antenna Technology and Applied Electromagnetics (ANTEM). Montreal (QC, Canada), 2016, p. 1-2. DOI: 10.1109/ANTEM.2016.7550145

[27] REZAIESARLAK, R., MANTEGHI, M. Complex-naturalresonance-based design of chipless RFID tag for high-density data. IEEE Transactions on Antennas and Propagation, 2014, vol. 62, no. 2, p. 898-904. DOI: 10.1109/TAP.2013.2290998

[28] HABIB, A., AZAM, M. A., AMIN, Y., et al. Chipless slot resonators for IoT system identification. In IEEE International Conference on Electro Information Technology (EIT). Grand Forks (ND), 2016, p. 0341-0344. DOI: 10.1109/EIT.2016.7535262

[29] VENA, A., PERRET, E., TEDJINI, S. Chipless RFID tag using hybrid coding technique. IEEE Transactions on Microwave Theory and Techniques, 2011, vol. 59, no. 12, p. 3356-3364. DOI: 10.1109/TMTT.2011.2171001

[30] SUMI, M., DINESH, R., NIJAS, C. M., et al. Frequency coded chipless RFID tag using spurline resonators. Radioengineering, 2014, vol. 23 , no. 1 , p. 203-208. ISSN: 1805-9600

[31] ZUO, Y. Survivable RFID systems: Issues, challenges, and techniques. IEEE Transactions on Systems, Man, and Cybernetics, Part C (Applications and Reviews), 2010, vol. 40, no. 4, p. 406 to 418. DOI: $10.1109 /$ TSMCC.2010.2043949

[32] YANG, C., SHEN, W., WANG, X. Applications of internet of things in manufacturing. In IEEE 20th International Conference on Computer Supported Cooperative Work in Design (CSCWD). 
Nanchang (China), 2016, p. 670-675. DOI: 10.1109/CSCWD.2016.7566069

[33] Wikimedia Foundation, Inc. Near and Far Field. 6 pages. [Online] Cited 2016-09-25. Available at: https://en.wikipedia.org /wiki/Near and far_field

[34] MARTINEZ, M., WEIDE, D. V. D. Circular polarization on depolarizing chipless RFID tags. In IEEE Radio and Wireless Symposium (RWS). Austin (TX, USA), 2016, p. 145-147. DOI: 10.1109/RWS.2016.7444388

[35] DOBKIN, D. M. The RF in RFID: Passive UHF RFID in Practice. Elsevier Inc, 2008. ISBN: 978-0-7506-8209-1

[36] BALANIS, C. A. Antenna Theory, Analysis and Design. Wiley, 2005. ISBN: 0-471-66782-X

[37] JANKOWSKI-MIHUŁOWICZ, P., WĘGLARSKI, M. Determination of passive and semi-passive chip parameters required for synthesis of interrogation zone in UHF RFID systems. Elektronika Ir Elektrotechnika, 2014, vol. 20, no. 9, p. 65-73. DOI: 10.5755/j01.eee.20.9.5007

[38] XU, L., HUANG, K. Design of compact trapezoidal bow-tie chipless RFID tag. International Journal of Antennas and Propagation, 2015, 7 p. DOI: 10.1155/2015/502938

[39] JAVED, N., HABIB, A., AKRAM, A., et al. 16-bit frequency signatured directly printable tag for organic electronics. IEICE Electronics Express, 2016, vol. 13, no. 11, p. 1-6. DOI: 10.1587/elex.13.20160406

\section{About the Authors ...}

Hafsa ANAM is working as a research scholar at the Telecommunication Engineering Department, University of Engineering and Technology, Taxila, Pakistan. She has received her BSc degree in Telecommunication Engineering from the University of Engineering and Technology, Taxila, Pakistan in 2015. The same year, she joined the University of Engineering and Technology, Taxila as fulltime MS researcher under the supervision of Dr.Yasar Amin, where she is pursuing her master's degree focused on chipless RFID tags.

Ayesha HABIB is working as a research scholar at the Telecommunication Engineering Department, University of Engineering and Technology Taxila, Pakistan. She did her $\mathrm{BSc}$ in Telecommunication Engineering from the Army Public College of Management and Sciences, in 2012. She has completed her MSc. in Telecommunication Engineering from the University of Engineering and Technology, Taxila, Pakistan in 2014. In 2014, she has joined ACTSENA research group as a research scholar and has started her Ph.D. under the supervision of Dr. Yasar Amin. Her main research focus is on chipless RFID tags with integrated sensor.
Syeda Irum JAFRI is working as a lecturer at the Telecommunication Engineering Department, University of Engineering and Technology, Taxila, Pakistan. She has received her MSc. degree in Telecommunication in 2014, from UET, Taxila, Pakistan. Her area of specialization is antenna system design.

Yasar AMIN is a Chairman and Associate Professor of the Telecommunication Engineering Department, University of Engineering and Technology, Taxila, Pakistan. He is the founder of ACTSENA Research Group at UET Taxila, Pakistan. He did his BSc. in Electrical Engineering in 2001 with specialization in Telecommunication, and M.Sc. in Electrical Engineering in 2003 with specialization in System-on-Chip Design from the Royal Institute of Technology (KTH), Sweden. His Ph.D. is in Electronic and Computer Systems from the Royal Institute of Technology (KTH), Sweden, with the research focus on printable green RFID antennas for embedded sensors, while he has MBA in Innovation and Growth from Turku School of Economics, University of Turku, Finland. He has done several specialized courses from Stanford University, California, USA and Massachusetts Institute of Technology (MIT), USA. He has supervised over 15 M.Sc. thesis, and presently supervising 8 doctoral thesis. He is presently serving as a leading Guest Editor at two international journals and an active reviewer of more than a dozen well reputed international journals. He has contributed to over 20 journal papers, over 30 reviewed international conference papers. Dr. Yasar is a member of IEEE, IET, ACM and ACES.

Hannu TENHUNEN is a chair professor of Electronic Systems at Royal Institute of Technology (KTH), Stockholm, Sweden. Prof. Tenhunen has held professor position as full professor, invited professor or visiting honorary professor in Finland (TUT, UTU), Sweden (KTH), USA (Cornel U), France (INPG), China (Fudan and Beijing Jiaotong Universities), and Hong Kong (Chinese University of Hong Kong), and has an honorary doctorate from Tallinn Technical University. He has been the director of multiple national large-scale research programs or being an initiator and director of national or Knowledge and Innovation Community EIT ICT Labs.European graduate schools. He has actively contributed to VLSI and SoC design in Finland and Sweden via creating new educational programs and research directions, most lately at European level as being the EU-level Education Director of the new European flagship initiative European Institute of Technology and Innovations (EIT), and its Knowledge and Innovation Community EIT ICT Labs. 